\title{
Vida média e obsolescência da literatura em educação indígena
}

\author{
Half life and obsolescence of literature in indigenous education
}

\author{
Alexandre Masson Maroldi \\ Doutor em Educação pela Universidade Federal de São Carlos - UFSCar. \\ Professor Adjunto da Universidade Federal de Rondônia. \\ E-mail: alexandre@unir.br \\ Luis Fernando Maia Lima \\ Doutor em Engenharia Civil - Hidráulica pela Universidade de São Paulo - USP. \\ Associado II da Universidade Federal de Rondônia. \\ E-mail: maialima2000@gmail.com \\ Maria Cristina Piumbato Innocentini Hayashi \\ Doutora em Educação pela Universidade Federal de São Carlos - UFSCar. \\ Professor Titular da Universidade Federal de São Carlos - UFSCar. \\ E-mail: dmch@ufscar.br
}

\section{Resumo}

A vida média é um indicativo da razão de obsolescência da literatura científica e permite determinar a idade e o declínio da literatura utilizada em uma determinada área de conhecimento. O presente artigo tem como objetivo discutir a complexidade do cálculo da vida média quando se analisam citações de livros, devido à questão do significado de uma obra considerada clássica no âmbito da Ciência da Informação, da Literatura e da Sociologia, e apresentar uma proposta de cálculo que leva em consideração a padronização do ano da obra citada. Com base nessa proposta foi realizada uma pesquisa empírica que determinou a vida média de 5.178 citações de livros presentes em 57 teses e 113 dissertações sobre educação indígena referentes ao período de 1996 e 2016, disponíveis na BDTD/IBICT. A vida média dos livros das Outras Áreas de Conhecimento é de 18,70 anos e de 18,83 anos na Área de Educação. Já os cálculos para o fator de envelhecimento revelaram o valor de 0,964 para as Outras Áreas do Conhecimento e a perda anual de atualidade da literatura consequentemente atinge 3,6\%, repetindo igualmente os mesmos números da Área de Educação, ou seja, as informações são desatualizadas lentamente.

Palavras-chave: Vida média e obsolescência. Bibliometria. Educação indígena.

\begin{abstract}
The average life is an indication of the reason of obsolescence of the scientific literature and allows to determine the age and the decline of the literature used in a certain area of knowledge. The purpose of this article is to discuss the complexity of the calculation of the average life when analyzing citations of books, due to the question of the meaning of a work considered classic in the scope of Information Science, Literature and Sociology, and present a proposal of calculation which takes into account the standardization of the year of the work cited. Based on this proposal, an empirical research was conducted that determined the average life of 5,178 citations from books present in 57 theses and 113 dissertations on indigenous education for the period 1996 and 2016, available at the BDTD / IBICT. The average life of the books in the Other Knowledge Areas is 18.70 years and 18.83 years in the Education Area. On the other hand, the calculations for the aging factor revealed a value of 0.964 for the Other Knowledge Areas, and the annual loss of current literature consequently reaches $3.6 \%$, also repeating the same numbers in the Education Area, that is, the information is outdated slowly.
\end{abstract}

Key words: Half life and obsolescence. Bibliometric. Indigenous education. 


\section{Introdução}

A Bibliometria compreende um conjunto de técnicas matemáticas e estatísticas utilizadas em diferentes situações, como por exemplo, na gestão de bibliotecas para selecionar e avaliar coleção de documentos; no apoio à política científica, por meio da descrição, análise e avaliação da atividade científica e de seus atores; e de avaliação da produção científica e tecnológica de áreas ou domínios de conhecimento específico (JIMÉNEZ-CONTRERAS, 2002). No entanto, estudos bibliométricos vão mais além do que um simples levantamento estatístico, de tal modo que as pesquisas com abordagens bibliométricas necessitam incorporar métodos qualitativos para fortalecer os resultados obtidos e superarem os questionamentos acerca da validade de investigações exclusivamente quantitativas. (SILVA; HAYASHI; HAYASHI, 2011).

No âmbito da abordagem bibliométrica, o conceito de "meia-vida" - do inglês half-life, ou "vida média" em português - tem origem na Física Nuclear para expressar o tempo de decomposição das substâncias radioativas. Burton e Kleber (1960) reportam que a área da documentação passou a utilizar dessa analogia para definir o tempo necessário para a obsolescência da literatura publicada ${ }^{1}$. Para os autores, no entanto, em relação à literatura científica o conceito de "half-life" é um pouco diferente, pois "ao contrário de uma substância radioativa que se torna diferente quando é desintegrada, a literatura simplesmente se torna inutilizada, mas não inutilizável. É obsoleta, mas não "desintegrada". (BURTON; KLEBER, 1960, p. 18-19). Ou seja, embora essa literatura não possa ser usada ela continua existindo. De Bellis (2009, p. 134) explica o significado do conceito de vida média:

É definido como o tempo durante o qual metade do uso total de uma determinada literatura foi feita. Na sua forma mais simples, se o uso é estimado por citações, ele é computado para um conjunto de documentos originais publicados em um determinado ano, subtraindo esse ano do ano de publicação mediano dos artigos citando os documentos. [...] Ou seja, o número esperado de citações acumuladas para os itens de origem diminui ano a ano pelo mesmo fator de envelhecimento.

Line e Sandison (1974) também problematizaram o conceito de obsolescência relacionando-o ao conceito de utilidade. Na visão dos autores, quando se fala na obsolescência

\footnotetext{
${ }^{1}$ Contudo, estudo mais recente (SZÁVA-KOVÁTS, 2002) baseado no exame dos usos anteriores do termo mostra a falta de fundamento para atribuir ao bibliotecário Burton e a o físico Kleber o termo e a noção do índice de "meia-vida" da obsolescência da literatura, bem como seus empréstimos da Física Nuclear e adaptação à literatura da obsolescência da literatura.
} 
da informação, é importante deixar claro se a preocupação é com documentos ou com as informações que eles contêm ao representar o conhecimento. Nas palavras dos autores:

\begin{abstract}
Se a preocupação é com o conhecimento, a "obsolescência" pode ser definida como um declínio da validade ou utilidade da informação, e pode ocorrer pelas seguintes razões: i) a informação é válida, mas foi incorporada em trabalhos posteriores; ii) a informação é válida, mas foi substituída por outras mais atuais; iii) a informação é válida, mas está em um campo de declínio de interesse; iv) as informações deixaram de ser consideradas válidas. (LINE; SANDISON, 1974, p. 283).
\end{abstract}

Três tipos de estudos de obsolescência da literatura foram apontados por Line e Sandison (1974, p. 286): os estudos sincrônicos, que seguem a citação de documentos ao longo do tempo; os diacrônicos, que analisam a distribuição etária dos documentos citados em um dado momento, e os estudos multisincrônicos, que comparam a distribuição etária de documentos citados em diferentes períodos de tempo permitindo assim a medição de mudanças nos processos de envelhecimento da literatura. Os autores ainda comentam que a grande maioria de estudos de obsolescência têm sido do tipo sincrônico, enquanto que os diacrônicos são mais raros devido às dificuldades encontradas em sua execução.

A vida média é um indicativo da razão de obsolescência da literatura científica e permite determinar a idade e o declínio da literatura utilizada em uma determinada área de conhecimento. Esses indicadores oferecem subsídios aos pesquisadores para que possam distinguir os trabalhos que são clássicos e aqueles que são efêmeros em sua área de conhecimento, permitindo se atualizarem em relação ao conhecimento produzido no campo de conhecimento em que atuam.

No Brasil, diversos estudos sobre vida média e a obsolescência da literatura foram realizados em diferentes áreas de conhecimento e tendo como objeto de estudo as citações de artigos científicos.

Já os estudos que analisaram a vida média de citações em teses e dissertações são menos frequentes na literatura científica brasileira. Por exemplo, o estudo de Arao, Santos e Guedes (2015) que buscou determinar a meia vida e a obsolescência do campo da Literatura tendo como base as citações que se encontravam na seção de referências das dissertações e teses do Programa de Pós-Graduação em Ciências da Literatura da Universidade Federal do Rio de Janeiro. Os resultados da pesquisa indicaram ser de 14 anos a vida média no período entre 2007 e 2008 e de 15 anos, no período entre 2011 e 2012. As autoras concluíram que essa é uma vida média relativamente longa em comparação aos estudos encontrados em outras áreas de conhecimento. 
Por sua vez, Osório e Oliveira (2010) realizaram um estudo que visou determinar a obsolescência da literatura utilizada pelos discentes da linha de pesquisa "Ensino, Aprendizagem Escolar e desenvolvimento Humano" do Programa de Pós-Graduação da UNESP - campus de Marília, em suas dissertações e teses, defendidas no ano de 2009. Os resultados apontaram que a literatura citada apresenta uma vida média de aproximadamente sete anos, considerado pelas autoras como uma "vida média jovem", sendo ainda observado que o fator de envelhecimento dessa literatura é de $90 \%$, ou seja, apresenta uma perda de $10 \%$ ano. (OSÓRIO; OLIVEIRA, 2010, p. 6).

Outro fator preponderante e que também despertou interesse para a realização dessa pesquisa é que na literatura científica praticamente não existem trabalhos que investigam a vida média e a obsolescência da literatura a partir da tipologia de livros, sendo mais comum esse tipo de cálculo apenas na literatura periódica, tamanha as particularidades que um livro possui principalmente com as diferentes datas de publicação.

Diante desse contexto essa pesquisa pretende identificar qual é a vida média, a obsolescência e a perda da atualidade da informação da literatura de livros sobre educação indígena citada nas dissertações e teses. Essa pesquisa pretende ainda discutir a questão dos livros clássicos no âmbito da Ciência da Informação, da Literatura e da Sociologia, bem como apresentar um cálculo padronizado para se obter a vida média e a obsolescência da literatura para livros.

\section{Vida média e obsolescência da literatura aplicada em livros: uma proposta}

Um particular aspecto a ser considerado nos cálculos estatísticos para obtenção da vida média e do fator de envelhecimento da literatura estudada diz respeito ao ano da publicação, pois a exatidão dessa informação é muito importante e influi na obtenção dos resultados da vida média e da obsolescência. Assim, quando o objeto de estudo é o artigo científico o ano da publicação é único, ou seja, o mesmo artigo não será publicado em anos diferentes, salvo nos raros casos em que determinados artigos são republicados em seções especiais de periódicos científicos, geralmente quando se trata de um artigo considerado "clássico" em determinadas áreas de conhecimento, ou em edições comemorativas dedicadas a revisitar a obra de algum pesquisador. 
No entanto, quando se tratam de estudos que utilizam o livro como tipologia documental, o ano da publicação se constitui em um problema complexo. Diferentemente dos artigos que têm apenas uma data de publicação, isto é, o ano em que foram publicados no periódico científico, em geral, ao longo do tempo, os livros podem ter várias edições, algumas delas motivadas por mudanças substanciais em seu conteúdo. Assim, cada edição recebe uma nova data, embora se trate da mesma obra. Ademais, o livro que teve várias edições - em especial aqueles que são traduzidos - pode ter mais de um prefácio, do próprio autor ou de outros, e também pode vir acompanhado de comentários de editores e tradutores, os quais nem sempre são reproduzidos em todas as edições. Isso influi na decisão dos leitores para a busca de uma edição específica que melhor se coadune com seus interesses. Muitas vezes, os pesquisadores consultam, por exemplo, a primeira edição em busca de um comentário do editor ou mesmo de um prefácio que tenha sido assinado por algum autor relevante à sua área do conhecimento.

Como se vê, quando o livro é objeto de estudo para o cálculo da vida média, o ano da publicação é bastante relevante. Ademais, um estudo bibliométrico rigoroso deve seguir critérios de normalização da informação ao transformar dados bibliográficos - no presente caso, as referências e as citações realizadas pelos autores das teses e dissertações - em dados bibliométricos, para garantir que os resultados sejam fidedignos e não comprometam as análises posteriores.

Desse modo, após a coleta das referências citadas nas teses e dissertações desse estudo, notou-se as seguintes ocorrências:

a) determinadas obras haviam sido citadas várias vezes com edições diferentes;

b) determinados autores das teses e dissertação citaram a mesma obra duas vezes em seus trabalhos, mas com anos diferentes;

c) determinados autores citaram no texto uma obra com determinado ano e na referência a obra é registrada com ano diferente;

d) alguns autores citaram obras com ano de publicação diferentes das edições referenciadas.

Essas variáveis poderiam influir nos resultados dos cálculos da vida média, do fator de envelhecimento e da perda anual da literatura citada. Essa constatação levou à opção pela 
normalização do ano de publicação dos livros citados, o que implicou em considerar a data mais antiga citada. ${ }^{2}$.

O Quadro 1, a seguir, apresenta um exemplo de um mesmo livro com diferentes datas de edição, e o "ano normalizado" adotado nesse trabalho.

Quadro 1 - Exemplo de obra com diferentes edições presentes na literatura citante

\begin{tabular}{|l|l|c|c|}
\hline \multicolumn{1}{|c|}{ Autor } & \multicolumn{1}{|c|}{ Título } & $\begin{array}{c}\text { Anos registrados } \\
\text { nas referências }\end{array}$ & $\begin{array}{c}\text { Ano } \\
\text { normalizado }\end{array}$ \\
\hline Stuart S. Hall & A identidade cultural na pós-modernidade & 1994 & 1994 \\
\hline Stuart S. Hall & A identidade cultural na pós-modernidade & 1997 & 1994 \\
\hline Stuart S. Hall & A identidade cultural na pós-modernidade & 1998 & 1994 \\
\hline Stuart S. Hall & A identidade cultural na pós-modernidade & 1999 & 1994 \\
\hline Stuart S. Hall & A identidade cultural na pós-modernidade & 2000 & 1994 \\
\hline Stuart S. Hall & A identidade cultural na pós-modernidade & 2001 & 1994 \\
\hline Stuart S. Hall & A identidade cultural na pós-modernidade & 2002 & 1994 \\
\hline Stuart S. Hall & A identidade cultural na pós-modernidade & 2003 & 1994 \\
\hline Stuart S. Hall & A identidade cultural na pós-modernidade & 2004 & 1994 \\
\hline Stuart S. Hall & A identidade cultural na pós-modernidade & 2005 & 1994 \\
\hline Stuart S. Hall & A identidade cultural na pós-modernidade & 2006 & 1994 \\
\hline Stuart S. Hall & A identidade cultural na pós-modernidade & 2011 & \\
\hline
\end{tabular}

Fonte: Elaborada pelos autores

Pode-se observar que a obra com o mesmo título foi citada com onze datas diferentes de publicação, provavelmente porque se referem a várias edições, ou porque foram registradas incorretamente nos trabalhos citantes.

\section{A importância dos "clássicos" nas análises de vida média de livros}

Para Burton e Kleber (1960) a literatura periódica - isto é, aquela publicada em periódicos científicos - de um campo temático pode ser composta por dois tipos distintos de literatura: a efêmera e a clássica. Para esses autores, a literatura efêmera, por sofrer constantes mudanças, tem uma vida média mais curta, tais como a literatura da Física e das Engenharias. Já a literatura clássica tem uma vida média mais longa, por exemplo, a da Geologia e da Botânica. Todavia, na visão desses autores algumas outras literaturas, como a da Química, possuem um caráter intermediário de envelhecimento. Apesar de meritório o trabalho de Burton

\footnotetext{
${ }^{2}$ Ao contrário do ano de início dos periódicos que podem ser rapidamente localizados por meio de consulta no Catálogo Coletivo Nacional (CCN), a busca do ano da primeira edição dos livros demandaria uma consulta inicial na Biblioteca Nacional, e no caso do depósito legal não ter sido feito o recurso seria consultar as editoras, o que demandaria um tempo de execução não exequível para os limites de dessa pesquisa. No entanto, apesar dessa ideia ter sido abandonada nesse momento, não se descarta a sua aplicação em futuros trabalhos.
} 
e Kleber (1960) ao inaugurarem os conceitos de vida média e de obsolescência da literatura aplicados à Ciência da Informação, vale observar alguns aspectos relevantes: primeiro, os autores estudaram literaturas de várias áreas de conhecimento, contudo nenhuma delas é relativa ao campo das Ciências Humanas; e segundo, embora tivessem sugerido que estudos adicionais sobre a literatura consolidada em livros devessem ser realizados, o objeto de estudo dessas literaturas foram artigos publicados em periódicos científicos. Além disso, o conceito de "clássico" e "efêmero" para Burton e Kleber (1960) refere-se à idade do documento, e não se o seu conteúdo propriamente dito já está ultrapassado. Ou seja, fatores como a tipologia documental (por exemplo, livros e artigos) e as características específicas que influem nos processos de comunicação científica e na dinâmica de publicação de cada campo de conhecimento foram relativizadas para esses autores. Por último, mas não menos importante, Burton e Kleber (1960, p. 20) ainda mencionam que:

É possível que a literatura periódica de um campo temático seja composta de dois ou mais tipos distintos de literatura, cada uma com a sua própria vida média. Há, por exemplo, na maioria dos campos, um corpo de literatura que é referido como a literatura clássica. Presumivelmente, esta literatura clássica tem uma vida média relativamente mais longa do que a chamada literatura efêmera, como é encontrada nas publicações de notícias semanais. Certamente, esse problema deve ser investigado mais detalhadamente.

Contudo, definir exatamente quando determinada literatura científica torna-se obsoleta é uma questão complexa. Line e Sandison (1974, p. 283) problematizaram este aspecto ao argumentaram:

O que se entende precisamente por 'obsolescência'? Se algo é cada vez menos utilizado, diz-se 'obsolescência' e quando esse uso cessa é 'obsoleto'. No entanto, quando se fala da obsolescência da informação é importante ter claro se a preocupação é com os documentos, ou com a informação que eles contêm, representando conhecimento. Se documentos estão sendo considerados, o interesse geralmente se detém sobre as probabilidades práticas de quais itens serão mantidos e da necessidade de um guia sobre como e quando descartar volumes mais antigos, quanto tempo manter os novos, que tipo de armazenamento retrospectivo e de acesso a um sistema de recuperação de informação será fornecido, e assim por diante. Se a preocupação é com o conhecimento, a 'obsolescência' pode ser definida como um declínio ao longo do tempo na validade ou utilidade da informação.

Mas não é só a Ciência da Informação que traz em seu bojo a discussão sobre o conceito de "clássico", que também pode ser encontrada principalmente na Literatura e em outras áreas de conhecimento. Para García Jurado (2010, p. 273) o conceito de "clássico" juntamente com o de "cânone" é um dos mais controversos quando se fala de literatura, haja vista que "a história do termo e suas transformações conceituais mostra um processo complexo no qual intervieram diversos aspectos como a gramática, a estética, a história e até mesmo o próprio acaso". García Jurado (2010, p. 290) também reputa a Ítalo Calvino o fato de ser o primeiro autor a reformular 
o conceito de clássicos a partir dos anos de 1980 do século XX. Em sua célebre obra Por que ler os clássicos, Calvino (1993) não traz uma definição específica para o que seja um clássico, mas sim um conjunto de catorze orientações do que considera uma obra clássica, entre as quais destacamos a primeira: "Os clássicos são aqueles livros dos quais, em geral, se ouve dizer: 'Estou relendo ...' e nunca 'Estou lendo...'”. (CALVINO, 1993, p. 9), numa nítida demonstração de que o tempo pode transformar uma determinada obra em clássica, ou seja, o amadurecimento ou novas necessidades do leitor o faz reler um livro que já havia sido lido.

Outro autor que mostrou o contraste existente entre as orientações das ciências e das humanidades no entendimento do que seriam os grandes trabalhos clássicos foi o sociólogo Robert Merton (1968, p. 40-41):

Nas ciências mais exatas, a acumulação seletiva do conhecimento significa que as contribuições clássicas feitas por homens de gênio ou de grande talento, são amplamente desenvolvidas em obras posteriores, muitas vezes, por homens de talento muito menor [...]. Nas humanidades, cada trabalho clássico - cada poema, drama, romance, ensaio ou trabalho histórico - sendo observado diretamente, tende a continuar fazendo parte da experiência direta das sucessivas gerações de humanistas [...] o primeiro contato com os clássicos desempenha papel insignificante no trabalho dos cientistas da física, da biologia, mas tem grande importância no trabalho dos estudiosos de humanidades.

Na visão de Merton (1968, p. 49) “a função dos clássicos é a de proporcionar um modelo para o trabalho intelectual”. Todavia, ao assinalar a importância da releitura dos clássicos, uma vez que esses livros "desenvolvem novas ideias por meio do retorno a velhos textos no contexto do conhecimento contemporâneo" esse autor também argumenta que

Se o livro tem precisamente a mesma coisa a nos dizer na segunda leitura, estamos sofrendo de severa estagnação intelectual, ou o trabalho clássico tem menos profundidade intelectual do que julgávamos, ou se dão simultaneamente essas duas infelizes circunstâncias. (MERTON, 1968, p. 50).

Para Nunes (2015, p. 407), “a questão dos clássicos é complexa quando vista a partir da Sociologia", uma vez que "novas categorias aparecem; entre elas a de precursores, fundadores e pioneiros", diferentemente da questão de 'clássico' como abordado na literatura. O autor cita duas pesquisas sobre "clássicos" na Sociologia. A primeira, realizada durante o Congresso Mundial de Sociologia ocorrido no Canadá em 1998, promovido pela International Sociological Association (ISA) que objetivou realizar uma "avaliação crítica da herança sociológica do século XX" e resultou em uma lista dos dez autores e obras considerados os mais influentes pelos sociólogos membros da ISA, entre eles: Pierre Bourdieu, Norbert Elias e Jürgen Habermas. Entretanto, nessa lista "alguns dos "clássicos" do século XIX e primeiros 
anos do século XX estão ausentes" (NUNES, 2015, p. 408), entre eles, por exemplo, Comte, Durkheim, Marx.

Nunes (2015, p. 410) também cita outra pesquisa realizada por Schwartzman (2000) sobre os "clássicos" da Sociologia brasileira em que 49 cientistas sociais indicaram dez obras e autores mais importantes e influentes nesse campo de conhecimento. Schwartzman (2000, p.4) ao refletir sobre a utilidade dos clássicos conclui que: "esses autores continuam bem presentes na mente de nossos cientistas sociais, definindo suas questões e apontando caminhos e descaminhos para a busca de respostas".

\section{Procedimentos metodológicos}

A fonte de dados foi a Biblioteca Digital Brasileira de Teses e Dissertações (BDTD) mantida pelo Instituto Brasileiro de Informação em Ciência e Tecnologia (IBICT) que reúne em um só portal as teses e dissertações defendidas em todo o País e por brasileiros no exterior.

Para coleta de dados da pesquisa na base de dados da BDTD foram escolhidas as expressões "educação indígena" e "educação escolar indígena". No total foram recuperados 170 trabalhos entre os anos de 1996 e 2016, isto é, dissertações de mestrado acadêmico ( $n=109$ ), dissertações de mestrado profissional $(n=4)$ e teses de doutorado $(n=57)$. Para a realização da análise de citações foram extraídas desse corpus as referências de livros $(\mathrm{n}=5.178)$, ou seja, todos os livros listados no final dos trabalhos dos autores das teses e dissertações, as quais foram categorizadas em duas áreas: a primeira, referente às citações presentes nos trabalhos da Área de Educação, e a segunda, com as referências presentes nas demais áreas - Ciências Humanas, Ensino, Linguística, Letras e Artes, Ciências Sociais Aplicadas, Ciências Ambientais e Interdisciplinar - aqui denominadas como Outras Áreas de Conhecimento. Após o desmembramento por áreas o corpus de análise foi constituído por: Área de Educação (n=99), sendo dissertações de mestrado acadêmico $(n=65)$, dissertações de mestrado profissional $(n=1)$ e teses de doutorado $(n=33)$, totalizando $n=3.313$ citações de livros; Outras Áreas de Conhecimento $(n=71)$, sendo dissertações de mestrado acadêmico $(n=44)$, dissertações de mestrado profissional $(n=3)$ e teses de doutorado $(n=24)$, totalizando 1.865 citações de livros. Tal desmembramento havia sido sugerido no trabalho de Arao (2014) que estudando a vida média constantes nas teses e dissertações do Programa de Pós-Graduação em Ciência da Literatura da Faculdade de Letras da Universidade Federal do Rio de Janeiro (UFRJ), 
recomenda que as análises das áreas de conhecimento sejam efetuadas separadamente para melhor compreender as particularidades de cada campo.

Na sequência, com o auxílio do software Excel foi elaborada uma planilha para análise das citações dos livros referenciados no conjuntos das teses e dissertações recuperadas no campo da educação indígena. Após o registro dos dados os mesmos foram modelados visando eliminar inconsistências, tais como registros repetidos e inconsistência nas datas de publicação, bem como a padronização das mesmas. Por último, ainda com o auxílio do software Excel foi elaborado os cálculos da vida média, da obsolescência da literatura e da perda anual de informação.

A seguir descrevemos detalhadamente como foram realizados os cálculos para a obtenção da vida média, obsolescência e perda anual de atualidade da literatura de livros

Conforme já comentado anteriormente, a vida média e a obsolescência da literatura podem ser calculadas conforme os procedimentos descritos nos estudos de Burton e Kleber (1960); Brookes (1970); Line e Sandison (1974). Assim, para o estudo da vida média seguiram as orientações de Brookes (1970).

Para a obtenção do fator anual de envelhecimento e perda anual da literatura adotaramse as sugestões de Brookes (1970) por meio do método sincrônico, conforme sugerido por Line e Sandison (1974). Contudo, antes de apresentar os resultados obtidos descrevem-se detalhadamente os cálculos estatísticos.

A vida média (h) é a idade (representada em anos) em que a literatura citada apresenta o seu ponto médio de diminuição no número de citações, ou seja, é reduzida pela metade (50\%). Pode ser obtida por meio do cálculo da mediana (Md) por interpolação linear.

Para isso foi elaborada uma tabela contendo as seguintes colunas:

1) ano das publicações - corresponde aos anos em que o documento foi publicado;

2) frequência absoluta $(f i)$ - valores recebidos pelas citações no ano;

3) frequência acumulada absoluta (Fia) -valores acumulados das citações em ordem cronológica inversa, isto é, da mais recente para a mais antiga;

4) frequência acumulada relativa (Fir) -valores percentuais acumulados das citações;

5) idade - começando pelo zero (0) para o ano mais recente e os demais valores em ordem crescente até atingir a idade correspondente ao último ano obtido na publicação e registrado na coluna 1 . 
Em seguida calculou-se o valor correspondente à posição da mediana na Tabela, denominado de "pos", que foi obtido pela somatória $\sum f i$ da coluna da frequência absoluta. Esse resultado será utilizado para localizar na Tabela as classes com frequência acumulada (Fir) imediatamente superior à posição "pos" da mediana .

O passo seguinte foi efetuar o cálculo da mediana por meio da interpolação linear utilizando a seguinte fórmula:

$$
M d=l+\left(\left(\frac{n}{2}\right)-F_{\text {ant }}\right) / f i *(L-l) \quad \text { onde: }
$$

$f i=$ frequência absoluta

$n=$ tamanho da amostra

$\left(\frac{n}{2}\right)=$ a posição da mediana, calculada pelo $\sum f i$

$l$ e $L=$ limite inferior (l) e limite superior (L) da classe mediana

$F_{\text {ant }}=$ frequência absoluta acumulada anterior à classe mediana.

O valor da mediana (Md) obtido pelo método da interpolação linear representa a vida média (h) da literatura analisada e seu valor numérico representa o total de anos - ou seja, a idade - para que a utilidade desta literatura seja reduzida em $50 \%$.

Obtida a vida média (h) foi possível calcular a obsolescência ou fator anual de envelhecimento de uma literatura (a) que representa o declínio da utilidade da literatura ao longo de um determinado tempo. Para isso, utiliza-se a seguinte fórmula:

$$
a=(0,5)^{1 / h}
$$

onde:

$\mathrm{a}=$ fator de envelhecimento anual ou obsolescência

$\mathrm{h}=$ vida média

Conforme Brookes (1970), o resultado dessa fórmula é expresso em um valor entre 0 (zero) e 1 (um). Desse modo, quanto mais se aproxima do 1 (um) a utilidade da literatura é maior, significando que o fator anual de envelhecimento é reduzido.

Por sua vez, o valor da perda anual da literatura é obtido mediante a utilização da equação 1-a. Em um exemplo hipotético, se o fator anual de envelhecimento é 0.96, que pode ser expresso no valor relativo de $96 \%$, a perda anual de literatura será de $4 \%$, representando o decréscimo anual da utilidade da literatura analisada. 


\section{Vida média, obsolescência e perda anual de atualidade da literatura de livros da Área de Educação}

A utilização da mediana por interpolação linear permitiu obtenção do valor de 18.83 anos para a vida média dos livros na Área de Educação (Tabela 1). Esse resultado está em consonância com a literatura do tipo clássica, e portanto mais longa, típica das Ciências Humanas, conforme exposto no estudo de Burton e Kleber (1960). Ou seja, o valor de 18.83 anos representa o tempo consumido para que a utilidade da literatura de livros de Educação citados nas teses e dissertações sobre educação indígena seja reduzida em $50 \%$.

Tabela 1 - Vida média dos livros citados na Área de Educação

\begin{tabular}{|c|c|c|c|c|}
\hline $\begin{array}{c}\text { Ano da } \\
\text { publicação }\end{array}$ & $\begin{array}{l}\text { Frequência das } \\
\text { citações }(f i)\end{array}$ & $\begin{array}{c}\text { Frequência } \\
\text { acumulada } \\
\text { Absoluta (Fia) }\end{array}$ & $\begin{array}{c}\text { Frequência } \\
\text { acumulada } \\
\text { relativa } \operatorname{Fir}(\%)\end{array}$ & Idade \\
\hline 2014 & 5 & 5 & 0,15 & 0 \\
\hline 2013 & 4 & 9 & 0,27 & 1 \\
\hline 2012 & 21 & 30 & 0,91 & 2 \\
\hline 2011 & 18 & 48 & 1,45 & 3 \\
\hline 2010 & 24 & 72 & 2,17 & 4 \\
\hline 2009 & 45 & 117 & 3,53 & 5 \\
\hline 2008 & 55 & 172 & 5,19 & 6 \\
\hline 2007 & 44 & 216 & 6,52 & 7 \\
\hline 2006 & 69 & 285 & 8,60 & 8 \\
\hline 2005 & 74 & 359 & 10,84 & 9 \\
\hline 2004 & 91 & 450 & 13,58 & 10 \\
\hline 2003 & 122 & 572 & 17,27 & 11 \\
\hline 2002 & 127 & 699 & 21,10 & 12 \\
\hline 2001 & 135 & 834 & 25,17 & 13 \\
\hline 2000 & 166 & 1000 & 30,18 & 14 \\
\hline 1999 & 119 & 1119 & 33,78 & 15 \\
\hline 1998 & 116 & 1235 & 37,28 & 16 \\
\hline 1997 & 155 & 1390 & 41,96 & 17 \\
\hline 1996 & 128 & 1518 & 45,82 & 18 \\
\hline 1995 & 167 & 1685 & 50,86 & 19 \\
\hline 1994 & 121 & 1806 & 54,51 & 20 \\
\hline 1993 & 65 & 1871 & 56,47 & 21 \\
\hline 1992 & 93 & 1964 & 59,28 & 22 \\
\hline 1991 & 71 & 2035 & 61,42 & 23 \\
\hline 1990 & 98 & 2133 & 64,38 & 24 \\
\hline 1989 & 84 & 2217 & 66,92 & 25 \\
\hline 1988 & 77 & 2294 & 69,24 & 26 \\
\hline 1987 & 70 & 2364 & 71,36 & 27 \\
\hline 1986 & 115 & 2479 & 74,83 & 28 \\
\hline 1985 & 47 & 2526 & 76,25 & 29 \\
\hline 1984 & 48 & 2574 & 77,69 & 30 \\
\hline 1983 & 86 & 2660 & 80,29 & 31 \\
\hline 1982 & 43 & 2703 & 81,59 & 32 \\
\hline 1981 & 47 & 2750 & 83,01 & 33 \\
\hline 1980 & 24 & 2774 & 83,73 & 34 \\
\hline 1979 & 63 & 2837 & 85,63 & 35 \\
\hline 1978 & 92 & 2929 & 88,41 & 36 \\
\hline 1977 & 35 & 2964 & 89,47 & 37 \\
\hline
\end{tabular}

InCID: R. Ci. Inf. e Doc., Ribeirão Preto, v. 9, n. 1, p. 109-129, mar./ago. 2018. 


\begin{tabular}{|c|c|c|c|c|}
\hline 1976 & 44 & 3008 & 90,79 & 38 \\
\hline 1975 & 41 & 3049 & 92,03 & 39 \\
\hline 1974 & 26 & 3075 & 92,82 & 40 \\
\hline 1973 & 20 & 3095 & 93,42 & 41 \\
\hline 1972 & 26 & 3121 & 94,20 & 42 \\
\hline 1971 & 5 & 3126 & 94,36 & 43 \\
\hline 1970 & 56 & 3182 & 96,05 & 44 \\
\hline 1969 & 13 & 3195 & 96,44 & 45 \\
\hline 1968 & 13 & 3208 & 96,83 & 46 \\
\hline 1967 & 24 & 3232 & 97,56 & 47 \\
\hline 1966 & 4 & 3236 & 97,68 & 48 \\
\hline 1965 & 6 & 3242 & 97,86 & 49 \\
\hline 1964 & 7 & 3249 & 98,07 & 50 \\
\hline 1963 & 4 & 3253 & $\begin{array}{l}98,19 \\
\end{array}$ & 51 \\
\hline 1962 & 18 & 3271 & 98,73 & 52 \\
\hline 1961 & 1 & 3272 & 98,76 & 53 \\
\hline 1959 & 6 & 3278 & 98,94 & 55 \\
\hline 1958 & 5 & 3283 & 99,09 & 56 \\
\hline 1957 & 1 & 3284 & 99,12 & 57 \\
\hline 1956 & 2 & 3286 & 99,19 & 58 \\
\hline 1955 & 1 & 3287 & 99,22 & 59 \\
\hline 1954 & 1 & 3288 & 99,25 & 60 \\
\hline 1953 & 3 & 3291 & 99,34 & 61 \\
\hline 1952 & 2 & 3293 & 99,40 & 62 \\
\hline 1949 & 2 & 3295 & 99,46 & 65 \\
\hline 1948 & 1 & 3296 & 99,49 & 66 \\
\hline 1946 & 1 & 3297 & 99,52 & 68 \\
\hline 1945 & 1 & 3298 & 99,55 & 69 \\
\hline 1944 & 2 & 3300 & 99,61 & 70 \\
\hline 1943 & 1 & 3301 & 99,64 & 71 \\
\hline 1942 & 1 & 3302 & 99,67 & 72 \\
\hline 1941 & 1 & 3303 & 99,70 & 73 \\
\hline 1940 & 2 & 3305 & 99,76 & 74 \\
\hline 1938 & 1 & 3306 & 99,79 & 76 \\
\hline 1937 & 1 & 3307 & 99,82 & 77 \\
\hline 1935 & 2 & 3309 & 99,88 & 79 \\
\hline 1928 & 1 & 3310 & 99,91 & 86 \\
\hline 1927 & 1 & 3311 & 99,94 & 87 \\
\hline 1908 & 1 & 3312 & 99,97 & 106 \\
\hline 1906 & 1 & 3313 & 100 & 108 \\
\hline Total & 3.313 & - & 100 & \\
\hline
\end{tabular}

Na Tabela 1, observa-se que a citação mais antiga $(n=1)$ publicada em 1906 ocorreu há 108 anos, e as mais recentes ocorreram no ano de 2014 (n=5), perfazendo um total de 78 anos de literatura citada no período.

O ano de 1995 ( $\mathrm{n}=167$ ) recebeu o maior número de citações seguido pelo ano 2.000 $(n=166)$. Nesse mesmo ano foram publicadas várias obras de autores de livros da Área de Educação entre eles Paulo Freire, bem como foram lançadas no Brasil traduções e novas edições das obras de Edgar Morin, Boaventura Sousa Santos e Norberto Elias e que podem ser considerados autores clássicos em sua área de conhecimento. A partir de então a frequência de 
citações começa a diminuir, demonstrando a perda de interesse dos autores das teses e dissertações sobre literatura indígena em uma literatura mais antiga.

O cálculo da obsolescência da literatura citada resultou em 0,964 , o que pode ser considerado um envelhecimento muito lento. Já a perda anual de atualidade das citações dessa tipologia de livros resultou em 3,6\% ao ano, o que corresponde a uma perda anual de atualização da informação muito lenta, também.

Em outras palavras, a cada ano que passa a diminuição de frequência das citações permanece em $3,6 \%$, o que indica um ritmo lento de perda da informação, ou seja, o uso desta literatura é $50 \%$ menor a cada 18,83 anos.

Por sua vez, ao organizar por períodos os dados da frequência absoluta das citações de livros da Área de Educação (Tabela 2) é possível observar que nos quatro primeiros períodos, entre 1906 e 1969 a frequência de citações representa apenas 3,95\% (n=131) do total. No período imediatamente posterior, isto é, entre 1970 e 1979 esse valor quadruplica $(n=90)$ isto é, atinge $12,32 \%$ do total. O crescimento se acentua ( $\mathrm{n}=641)$ no período seguinte entre 1970 e 1979 quando atinge $19,35 \%$ do total de citações e atinge o $(n=1.133)$ entre 1990 e 1999 representando $34.20 \%$ do total. A partir do período entre 2000 e 2009 a frequência de citações começa a decrescer $(n=928)$ com 28,01\% e no período seguinte, compreendido entre 2000 e 2009 há uma queda acentuada $(n=72)$ representando 2,17\% no período entre 2010 e 2014.

Tabela 2 - Distribuição das citações de livros por período

\begin{tabular}{c|c|c|c}
\hline Período & $\begin{array}{c}\text { Frequência absoluta } \\
\text { de citações }\end{array}$ & $\begin{array}{c}\text { Frequência relativa } \\
\text { de citações (\%) }\end{array}$ & $\begin{array}{c}\text { Frequência } \\
\text { relativa (\%) }\end{array}$ \\
\hline $1906-1938$ & 8 & 0,24 & \multirow{2}{*}{3,95} \\
\hline $1940-1949$ & 12 & 0,36 & \\
\hline $1952-1959$ & 21 & 0,63 & 12,32 \\
\hline $1961-1969$ & 90 & 2,72 & 19,35 \\
\hline $1970-1979$ & 408 & 12,32 & 34,20 \\
\hline $1980-1989$ & 641 & 19,35 & 28,01 \\
\hline $1990-1999$ & 1.133 & 34,20 & 2,17 \\
\hline $2000-2009$ & 928 & 28,01 & $\mathbf{1 0 0}$ \\
\hline $2010-2014$ & 72 & 2,17 & \\
\hline Total & $\mathbf{3 . 3 1 3}$ & $\mathbf{1 0 0}$ &
\end{tabular}

Fonte: Elaborada pelos autores

Esses resultados confirmam que a perda anual de 3,6\% da literatura de livros de Educação é lenta, conforme já demonstrado anteriormente e dependente do uso de uma literatura mais antiga. Essas características encontradas são explicadas por Meadows e O’Connor (1970) ao afirmarem que no início de um campo do conhecimento o número de 
referências é mínimo, pois existe pouca ou nenhuma literatura prévia para citar, e cresce com o tempo até atingir um valor estacionário.

A partir dessas considerações, observa-se que o período entre os anos de 1906 e 1969 (3,95\%) é o maior em termos de duração de tempo (63 anos), mas com baixa frequência de citações. Esse pode ser considerado o período embrionário dos estudos indígenas no Brasil e a escassez de literatura desse período possivelmente podem ser atribuídos a dois fatores: a) como se observou anteriormente, o campo da educação indígena no Brasil é constituído de um número considerável de autores estrangeiros (tabelas 1 e 3), mas nesse período existiam poucas publicações internacionais traduzidas no país; b) em função da longevidade em que foram publicadas, muitas tiveram apenas uma edição, tornando-se de difícil acesso aos pesquisadores. Outras, por se constituírem em primeiras edições, somente são encontradas em grandes bibliotecas e quase sempre o acesso a esse material é restrito visando a sua preservação.

Nitidamente há um incremento considerável da frequência de citações entre a passagem da primeira fase, entre 1906 e 1969, para a segunda fase entre 1970 e 1979. Esse período corresponde ao surgimento dos primeiros trabalhos de pós-graduação voltados especificamente para o estudo da educação indígena, como, por exemplo, a dissertação de Nanci Antunes Tsupal defendida na área de Educação no ano de 1978. Esse período também é marcado como a década inicial de uma fase em que a educação indígena é pensada para o índio, ou seja, o modelo dominador e autoritário até então imposto durante os séculos passados é deixando de lado em função principalmente da presença do Estado brasileiro nas políticas públicas relacionadas à educação indígena.

Na fase posterior entre 1980 e 1989, como nota-se na tabela 2, há um novo aumento na frequência de citações, provavelmente como reflexo principalmente das políticas públicas advindas da década anterior. É ainda nessa década que a educação indígena alcança sua maior conquista com a promulgação em 1988 da Constituição Federal brasileira. Ganha corpo a partir de então a ideia de uma educação escolar indígena voltada especificamente para cada etnia, mantendo suas tradições educacionais, culturais e linguísticas.

A próxima década entre 1990 e 1999 é a fase de consolidação da educação escolar indígena no Brasil com uma a promulgação de extensa lista de leis, decretos e portarias que constituem o marco legal dessa educação e que vão fortalecendo e amadurecendo o campo, o que acaba por repercutir no incremento de citações de obras publicadas nesse período. 
O penúltimo período (2000-2009) é marcado pelo decrescimento no número de citações, fato esse ocorrido pela primeira vez. Em nosso entendimento, nessa década inicia-se o processo de estabilidade da literatura (MEADOWS; O’CONNOR, 1970), ou seja, há um processo de saturação dos paradigmas atuais existentes, pois os mesmos já foram discutidos anteriormente.

\section{Análise da vida média, obsolescência e perda anual de atualidade da literatura de livros das Outras Áreas do Conhecimento}

A Tabela 3 apresenta os dados que permitiram calcular a vida média dos livros citados em Outras Áreas de Conhecimento.

Tabela 3 - Vida média dos livros citados nas Outras Áreas do Conhecimento

\begin{tabular}{|c|c|c|c|c|}
\hline $\begin{array}{c}\text { Ano da } \\
\text { publicação }\end{array}$ & $\begin{array}{l}\text { Frequência das } \\
\text { citações }(f i)\end{array}$ & $\begin{array}{c}\text { Frequência } \\
\text { acumulada } \\
\text { Absoluta (Fia) }\end{array}$ & $\begin{array}{c}\text { Frequência } \\
\text { acumulada } \\
\text { relativa } \operatorname{Fir}(\%)\end{array}$ & Idade \\
\hline 2014 & 2 & 2 & 0,11 & 0 \\
\hline 2013 & 1 & 3 & 0,16 & 1 \\
\hline 2012 & 18 & 21 & 1,13 & 2 \\
\hline 2011 & 22 & 43 & 2,31 & 3 \\
\hline 2010 & 20 & 63 & 3,38 & 4 \\
\hline 2009 & 53 & 116 & 6,22 & 5 \\
\hline 2008 & 46 & 162 & 8,69 & 6 \\
\hline 2007 & 49 & 211 & 11,31 & 7 \\
\hline 2006 & 49 & 260 & 13,94 & 8 \\
\hline 2005 & 39 & 299 & 16,03 & 9 \\
\hline 2004 & 56 & 355 & 19,03 & 10 \\
\hline 2003 & 85 & 440 & 23,59 & 11 \\
\hline 2002 & 61 & 501 & 26,86 & 12 \\
\hline 2001 & 62 & 563 & 30,19 & 13 \\
\hline 2000 & 62 & 625 & 33,51 & 14 \\
\hline 1999 & 59 & 684 & 36,68 & 15 \\
\hline 1998 & 66 & 750 & 40,21 & 16 \\
\hline 1997 & 58 & 808 & 43,32 & 17 \\
\hline 1996 & 67 & 875 & 46,92 & 18 \\
\hline 1995 & 82 & 957 & 51,31 & 19 \\
\hline 1994 & 50 & 1007 & 53,99 & 20 \\
\hline 1993 & 39 & 1046 & 56,09 & 21 \\
\hline 1992 & 31 & 1077 & 57,75 & 22 \\
\hline 1991 & 42 & 1119 & 60,00 & 23 \\
\hline 1990 & 25 & 1144 & 61,34 & 24 \\
\hline 1989 & 60 & 1204 & 64,56 & 25 \\
\hline 1988 & 63 & 1267 & 67,94 & 26 \\
\hline 1987 & 29 & 1296 & 69,49 & 27 \\
\hline 1986 & 45 & 1341 & 71,90 & 28 \\
\hline 1985 & 20 & 1361 & 72,98 & 29 \\
\hline 1984 & 18 & 1379 & 73,94 & 30 \\
\hline 1983 & 23 & 1402 & 75,17 & 31 \\
\hline 1982 & 43 & 1445 & 77,48 & 32 \\
\hline 1981 & 31 & 1476 & 79,14 & 33 \\
\hline 1980 & 36 & 1512 & 81,07 & 34 \\
\hline
\end{tabular}




\begin{tabular}{|c|c|c|c|c|}
\hline 1979 & 48 & 1560 & 83,65 & 35 \\
\hline 1978 & 43 & 1603 & 85,95 & 36 \\
\hline 1977 & 13 & 1616 & 86,65 & 37 \\
\hline 1976 & 37 & 1653 & 88,63 & 38 \\
\hline 1975 & 42 & 1695 & 90,88 & 39 \\
\hline 1974 & 11 & 1706 & 91,47 & 40 \\
\hline 1973 & 6 & 1712 & 91,80 & 41 \\
\hline 1972 & 19 & 1731 & 92,82 & 42 \\
\hline 1971 & 2 & 1733 & 92,92 & 43 \\
\hline 1970 & 31 & 1764 & 94,58 & 44 \\
\hline 1969 & 12 & 1776 & 95,23 & 45 \\
\hline 1968 & 25 & 1801 & 96,57 & 46 \\
\hline 1967 & 4 & 1805 & 96,78 & 47 \\
\hline 1966 & 2 & 1807 & 96,89 & 48 \\
\hline 1965 & 7 & 1814 & 97,27 & 49 \\
\hline 1964 & 8 & 1822 & 97,69 & 50 \\
\hline 1963 & 4 & 1826 & 97,91 & 51 \\
\hline 1962 & 9 & 1835 & 98,39 & 52 \\
\hline 1960 & 2 & 1837 & 98,50 & 54 \\
\hline 1959 & 2 & 1839 & 98,61 & 55 \\
\hline 1958 & 4 & 1843 & 98,82 & 56 \\
\hline 1957 & 3 & 1846 & 98,98 & 57 \\
\hline 1953 & 2 & 1848 & 99,09 & 61 \\
\hline 1952 & 4 & 1852 & 99,30 & 62 \\
\hline 1948 & 1 & 1853 & 99,36 & 66 \\
\hline 1946 & 1 & 1854 & 99,41 & 68 \\
\hline 1945 & 1 & 1855 & 99,46 & 69 \\
\hline 1943 & 4 & 1859 & 99,68 & 71 \\
\hline 1941 & 2 & 1861 & 99,79 & 73 \\
\hline 1939 & 2 & 1863 & 99,89 & 75 \\
\hline 1937 & 1 & 1864 & 99,95 & 77 \\
\hline 1935 & 1 & 1865 & 100,00 & 79 \\
\hline
\end{tabular}

Fonte: Elaborada pelos autores

A vida média dos livros das Outras Áreas de Conhecimento é de 18,70 anos, também considerada clássica, com valores muito próximos da vida média de livros na Área de Educação que foi de 18,83 anos, assim podemos afirmar que os padrões de citações de livros praticamente são os mesmos, tanto na Área de Educação quanto nas Outras Áreas do Conhecimento.

Os cálculos para o fator de envelhecimento revelaram o valor de 0,964 e a perda anual de atualidade da literatura consequentemente atinge 3,6\%, repetindo igualmente os mesmos números da Área de Educação, ou seja, as informações são desatualizadas lentamente.

A citação mais recente da tipologia livros, de acordo com dados exibidos na Tabela 3, ocorreu no ano de 2014 e a mais antiga ocorreu no ano de 1935, resultando um total de 79 anos, num total de 1.865 citações.

Já o ano de 2003 foi o que recebeu o maior número de citações $(\mathrm{n}=85)$. Procurando respostas para o alto grau de citações para esse ano, nota-se que não há um único autor com um título de livro em elevado número de citações, mas sim um equilíbrio entre os mesmos, podendo 
destacar a obra clássica dos estudos culturais contemporâneos Da diáspora, identidades $e$ mediações culturais de Stuart Hall e a obra também clássica da antropologia A sociedade contra o Estado de Pierre Clastres. Há ainda uma forte frequência de títulos de livros oriundas das temáticas da História, Antropologia, Educação e da Sociologia.

A seguir, a tabela 4 mostra a distribuição das citações de livros das Outras Áreas do Conhecimento organizada de acordo com períodos cronológicos específicos, o que permite observar outras características dessa literatura.

Tabela 4 - distribuição das citações de livros por período

\begin{tabular}{c|c|c|c}
\hline Período & $\begin{array}{c}\text { Frequência absoluta } \\
\text { de citações }\end{array}$ & $\begin{array}{c}\text { Frequência relativa } \\
\text { de citações }(\boldsymbol{\%})\end{array}$ & $\begin{array}{c}\text { Frequência } \\
\text { relativa }(\boldsymbol{\%})\end{array}$ \\
\hline $1935-1939$ & 4 & 0,2 & \multirow{2}{*}{5,4} \\
\hline $1941-1949$ & 9 & 0,5 & \\
\hline $1952-1959$ & 15 & 0,8 & 13,5 \\
\hline $1960-1969$ & 73 & 3,9 & 19,7 \\
\hline $1970-1979$ & 252 & 13,5 & 27,8 \\
\hline $1980-1989$ & 368 & 19,7 & 30,2 \\
\hline $1990-1999$ & 519 & 27,8 & 3,4 \\
\hline $2000-2009$ & 562 & 30,2 & $\mathbf{1 0 0}$ \\
\hline $2010-2014$ & 63 & 3,4 & $\mathbf{1 0 0}$ \\
\hline
\end{tabular}

A Tabela 4, assim como aconteceu na Área de Educação (Tabela 2), ao longo dos anos a literatura de livros citada nas Outras Áreas de Conhecimento também vem anotando um crescimento na frequência de citações, com exceção do último período entre 2010 e 2014 que apresentou um decréscimo acentuado quando comparado aos anteriores.

O período compreendido 2000 e 2009 quando a literatura citada atinge o seu ápice também pode ser considerado como aquele em que se inicia a fase de estabilidade dessa literatura. Ou seja, comparando as fases de estabilidade das literaturas de livros citadas nas áreas de Educação e Outras Áreas de Conhecimento, é possível observar que essas fases ocorrem em décadas diferentes, ou seja: 1990 e 1999 para a primeira, e imediatamente na década posterior para a segunda. 


\section{Considerações finais}

Com relação a vida média a partir do cálculo normalizado de livros na Área de Educação o valor obtido foi de 18,83 anos e das Outras Áreas de Conhecimento foi de 18,70 anos, que por sua características de idades são consideradas literaturas clássicas, uma vez que possuem uma vida média mais longa.

Assim como na Área de Educação, as Outras Áreas do Conhecimento também carecem de uma literatura mais atualizada, e nesse sentido observa-se que os resultados sobre a vida média e a obsolescência da informação, obtidas através da análise de citações utilizadas pelos autores das teses e dissertações, poderá contribuir para uma reflexão dessas áreas de conhecimento visando fortalecer as relações interdisciplinares entre as mesmas na busca de novos paradigmas interpretativos para a questão da educação indígena.

Destaca-se também que no cômputo final da vida média de livros da Área de Educação (18,83 anos), e das Outras Áreas do Conhecimento (18,70 anos) há poucas discrepâncias. Embora as citações das Outras Áreas do Conhecimento venham de várias áreas distintas isso não influenciou no resultado da vida média, quando comparado com a área de Educação, que é representada por citações extraídas de trabalhos de uma única área.

Outro aspecto a ser enfatizado nessa pesquisa diz respeito ao significado que as obras ditas "clássicas" assumem na literatura de áreas específicas de conhecimento quando se obtém resultados oriundos de análises bibliométricas, em especial pelas análises da vida média e da obsolescência oriundas dos livros e que podem auxiliar os bibliometristas nas discussões dos dados encontrados em suas pesquisas.

Ainda em relação vida média de livros, o cálculo proposto de normalização das datas de publicações sempre pela mais antiga citada em caso de repetição de uma mesma obra, mostrouse apropriado. Em vista disso, sugerimos que em futuros estudos que se proponham a calcular a vida média de livros seja adotada a normalização do ano das obras citadas sempre pela primeira edição, o que pode trazer novos indicativos e fortalecer ainda mais as análises e interpretações dos resultados. 


\section{Referências}

\section{ARAO, L. H. Vida média e obsolescência da área de ciência da literatura: uma} contribuição ao entendimento da cronologia de citações na atividade acadêmica.2014. $49 \mathrm{f}$. (Trabalho de Conclusão de Curso (Graduação em Biblioteconomia e Gestão da Informação), Universidade Federal do Rio de Janeiro, Rio de Janeiro, 2014.

ARAO, L. H.; SANTOS, M. J. V. C.; GUEDES, V. L. S. The Half-Life and Obsolescence of the Literature Science Area: a contribution to the understanding the chronology of citations in academic activity. In: QUALITATIVE AND QUANTITATIVE METHODS IN LIBRARIES INTERNATIONAL CONFERENCE (QQML), 7., 2015, Paris. Anais... Paris, 2015.

BROOKES, B. C. Obsolescence of special library periodicals: sampling errors and utility contours. Journal of the American Society for Information Science, v. 21, p. 320-329, set. 1970.

BURTON, R. E., KLEBER, R. W. The "half life" of some scientific and technical literatures. American Documentation, New York, v. 1, n. 1, p. 18-22, jan. 1960.

CALVINO, I. Por que ler os clássicos. São Paulo: Companhia das letras, 1993.

DE BELLIS, N. Bibliometrics and citation analysis: from the Science citation index to cybermetrics. Lanham, Md: Scarecrow, 2009.

GARCIA JURADO, F. La ciudad invisible de los clássicos: entre Aulo Gelio e Italo Calvino. Nova Tellus, v. 28, n. 1, p. 271-300, 2010.

JIMÉNEZ-CONTRERAS, E. La aportación española a la producción científica internacional en biblioteconomía y documentación: balance de diez años (1992-2001). Biblioteconomía y Documentación, v. 9, p. 1-29, 2002.

LINE, M. B.; SANDISON, A. Progress in documentation: 'obsolescence' and the changes in the use of literature with 'time'. Journal of Documentation, v. 30, n. 3, p. 283-350, 1974.

MEADOWS, A. J.; O'CONNOR J. G. Bibliographical statistics as a guide to growth points in science. Science Studies, v. 1, p. 95-99, 1970.

MERTON, R. K. La sociología de la ciencia. Madrid: Alianza, 1968.

NUNES, E. D. Dos clássicos na literatura aos clássicos na sociologia e na sociologia médica/saúde. Physis: Revista de Saúde Coletiva, Rio de Janeiro, v.25, n.2, p. 401-421, 2015.

OSÓRIO, H. P.; OLIVEIRA, E. F. T. Estudo da obsolescência da literatura em Educação pelos métodos do cálculo do máximo de citações, mínimos quadrados e vida média. In: ENCONTRO INTERNACIONAL DE INFORMAÇÃO, CONHECIMENTO E AÇÃO, 2010, 6., Marília, 2010. Anais... Marília: UNESP, 2010.

SCHWARTZMAN, S. As ciências sociais brasileiras no século 20. Ciência Hoje, Abril. 2000. 
SILVA, M. R.; HAYASHI, C. R. M.; HAYASHI, M. C. P. I. Análise bibliométrica e cientométrica: desafios para especialistas que atuam no campo. InCID: Revista de Ciência da Informação e Documentação, Ribeirão Preto, v. 2, n. 1, p. 110-129, jan./jun. 2011.

SZÁVA-KOVATZ, E. Unffounded attribution of the 'half-life' index-number of literature obsolescence to Burton and Kleber: a literature Science study. Journal of the Association for Information Science and Technology, v. 53, n. 13, p. 1098-1105, 2002. 